\title{
Collecting Heavy Metal Music
}

\author{
BY KARSON JONES \\ THE ROYAL CONSERVATORY
}

\section{Why Collect Heavy Metal?}

Heavy Metal, more than most forms of popular music, has endured scathing criticism from all sides. Music critics, politicians, and parent groups have all decried the musical degeneracy ${ }^{1}$ and moral decrepitude ${ }^{2}$ of the genre. In the face of this, however, metal has simply become more popular and more extreme in its sound, imagery, and values. Heavy metal music and culture has, for most of its existence, fallen very much outside the mainstream and in many ways defines itself as anti-establishment. Many might ask whether this music, being so frequently derided, is worthy of academic study and whether libraries should be adding it to their collections.

The fact is that, regardless of how one feels about the music and culture of heavy metal, an increasing amount of social scientific and musicological research is being done on the subject. There is also evidence that heavy metal is increasingly being included in post-secondary curricula. ${ }^{3}$ Research collections and archives are needed to support this study and teaching. These collections need to contain not only the academic literature and the seminal sound recordings, but also the visual art, fashion, and other ephemera that are inseparable from the metal experience. At various institutions, one will find substantial collections dedicated to other marginal genres and subgenres of music, national musics, and even individual bands or performers, yet metal has been, for the most part, ignored so far. ${ }^{4}$

There is a dearth of library literature on this topic. In 2002, Robert Freeborn performed a search in Library Literature for the keywords heavy metal and retrieved four results, only one of which was in English. He also cites a 1990 German article in which the author found that of eight universities, six had less then $1 \%$ of heavy metal content in relation to their entire music collections. ${ }^{5}$ Brian Hickam and Thomas Atwood repeated Freeborn's search in 2008 and found things only slightly improved: a total of 28 entries were uncovered in Library, Information Science \& Technology Abstracts, without counting book reviews. ${ }^{6}$ To this day, aside from some

\footnotetext{
${ }^{1}$ See Robert Walser, Running With the Devil: Power, Gender and Madness in Heavy Metal Music (Middletown, Conn.: Wesleyan University Press, 1993), 20-21.

${ }^{2}$ See 'Highway to Hell,' The Guardian, June 2, 2003, http://www.guardian.co.uk/world/2003/jun/02/worlddispatch.brianwhitaker (accessed April 2, 2011) ${ }^{3}$ Brian Hickman and Thomas Atwood, "Filling the Void: The Heavy Metal and Hardcore Punk Archiving Project," in The Metal Void: First Gatherings, ed. Nial W. R. Scott and Imke Von Helden (Oxford, United Kingdom: Inter-Disciplinary Press, 2010), 381-396, accessed March 30, 2011, http://www.interdisciplinary.net/wp-content/uploads/2010/04/mmp1ever3150410.pdf.

${ }^{4}$ Ibid., 386.

${ }^{5}$ Robert Freeborn, "Confronting the Dark Side of the Beat: A Guide to Creating a Heavy Metal Collection," Music Reference Services Quarterly 8, no. 2 (2002): 26.

${ }^{6}$ Hickman and Atwood, 385.
}

(C) 2011 The author and the Canadian Association of Music Libraries, Archives and Documentation Centres / L'auteur et l'Association canadienne des bibliothèques, archives et centres de documentation musicaux 
very limited and superficial surveys in magazines like Library Journal, ${ }^{7}$ Freeborn's article is the only substantial study of collection development in the area of heavy metal.

Yet, one can easily see that an increasing amount of academic work is being done on the genre. The following is a list of WorldCat records for books with the subject heading Heavy Metal (Music), indicating the number of titles published in each year, from 1980 to 2009. One can see a similar trend in the publication of academic articles on the subject. This, of course, is only a fraction of the large body of print, video, and online materials being created on the subject of heavy metal in various disciplines, as much of it is not collected and catalogued by OCLC participating libraries. However, it certainly indicates an upward trend:

$$
\begin{array}{ll}
\text { - } & 2009(60) \\
\text { - } & 2008(48) \\
\text { - } & 2007(43) \\
\text { - } & 2006(34) \\
\text { - } & 2004(38) \\
\text { - } & 2003(28) \\
\text { - } & 2002(38) \\
\text { - } & 2001(23) \\
\text { - } & 1990(19) \\
\text { - } & 1998(11) \\
\text { - } & 1997(10) \\
\text { - } & 1996(12) \\
\text { - } & 1995(10) \\
\text { - } & 1994(8) \\
\text { - } & 1993(24) \\
\text { - } & 1992(8) \\
\text { - } & 1991(16) \\
\text { - } & 1989(6) \\
\text { - } & 1988(6) \\
\text { - } & 1987(4) \\
\text { - } & 1986(4) \\
\text { - } & 1985(12) \\
\text { - } & 1984(3) \\
\text { - } & 1983(1) \\
\text { - } & 1980(2) \\
\hline &
\end{array}
$$

This is not to suggest that all music libraries should be collecting heavy metal, but those with substantial programs in popular music studies, cultural studies, and the like would do well to consider creating a basic collection. Hickam and Atwood also believe that there is a need to create an archive, either centralized or distributed, of heavy metal music covering "all formats, mediums, languages, geographic locations, and eras." ${ }^{8}$ In 2008, they began a cooperative project between Bowling Green State University's Sound Recordings Archive and the University of Toledo to create such a repository, and are currently looking for other institutions in North America and around the world to work with on their mission.

\footnotetext{
${ }^{7}$ See, for example, Matthew Moyer, "Metal: Headbang for Your Buck," Library Journal (2008).

${ }^{8}$ Hickman and Atwood, 384.
} 
Until recently, no such repository existed in Canada. In 2008, York University began taking steps toward creating a metal collection. Martin Popoff, the Toronto-based heavy metal collector and author of a number of books on the subject began selling curated portions of his collection to York's Sound and Moving Images Library. After several hundred metal CDs were added to the collection, Rob van der Bliek, the Music Librarian, and I, the music cataloguer at the time, began to take a more intentional and planned approach to building this special collection. Ultimately, holdings grew to over $700 \mathrm{CDs}$, including most of the seminal sound recordings in each major subgenre, as well as a large number of books and periodicals on the subject. This project is ongoing and, as far as I know, has resulted in the largest body of heavy metal recordings, books, and periodicals to be held at any Canadian university.

The project has also led to an examination into the nature of heavy metal subgenres, the important recordings from each, and some of the difficulties in effectively collecting and cataloguing this material. The remainder of this paper is concerned with these issues, in the hopes of inspiring other Canadian music libraries to build similar collections.

\section{Understanding Heavy Metal GenRes}

My intent in the following section is to introduce some of the principal subgenres of heavy metal, in order to increase music librarians' understanding of the broad range of styles that need to be covered in a collection development strategy. Heavy metal is the object of a great deal of bias and lack of respect; I hope that a better understanding of the music will help to overcome some of this.

There is a constant concern among fans, critics, and performers of metal music with drawing fine distinctions between who is and who is not metal, and with determining where in the dizzying collection of metal subgenres a particular band belongs. With the possible exception of electronic dance music, there is no other form of popular music that has fragmented into so many distinct styles. This proliferation and the fine distinctions that are made can be somewhat daunting to the uninitiated.

Many attempts have been made to create visual guides to this generic diffusion, with varying results. Often these charts and tables only serve to confuse the matter-drawing thick borders where there should be broad smudges, defining precedents without historical justification, and using nomenclature that runs contrary to common usage. Such diagrams can, however, be useful for displaying the broad categories and well-documented relationships, helping newcomers to the music grasp these basic categories and relationships. For an example of one such visual guide, see figure 1.

For the most part, heavy metal genres have been created and perpetuated by performers and fans, rather than by critics, record labels, and the media. Most metal subgenres are more than marketing categories; they follow a distinct and well-defined code, or set of rules. These rules are initially exemplified by a band or collection of bands and then picked up and codified by other bands and fans until a unique designation gets applied to the style. Each subgenre is often more than simply a variation in instrumentation, compositional, and performance techniques, but includes other dimensions related to visual style, lyrical themes, and other 


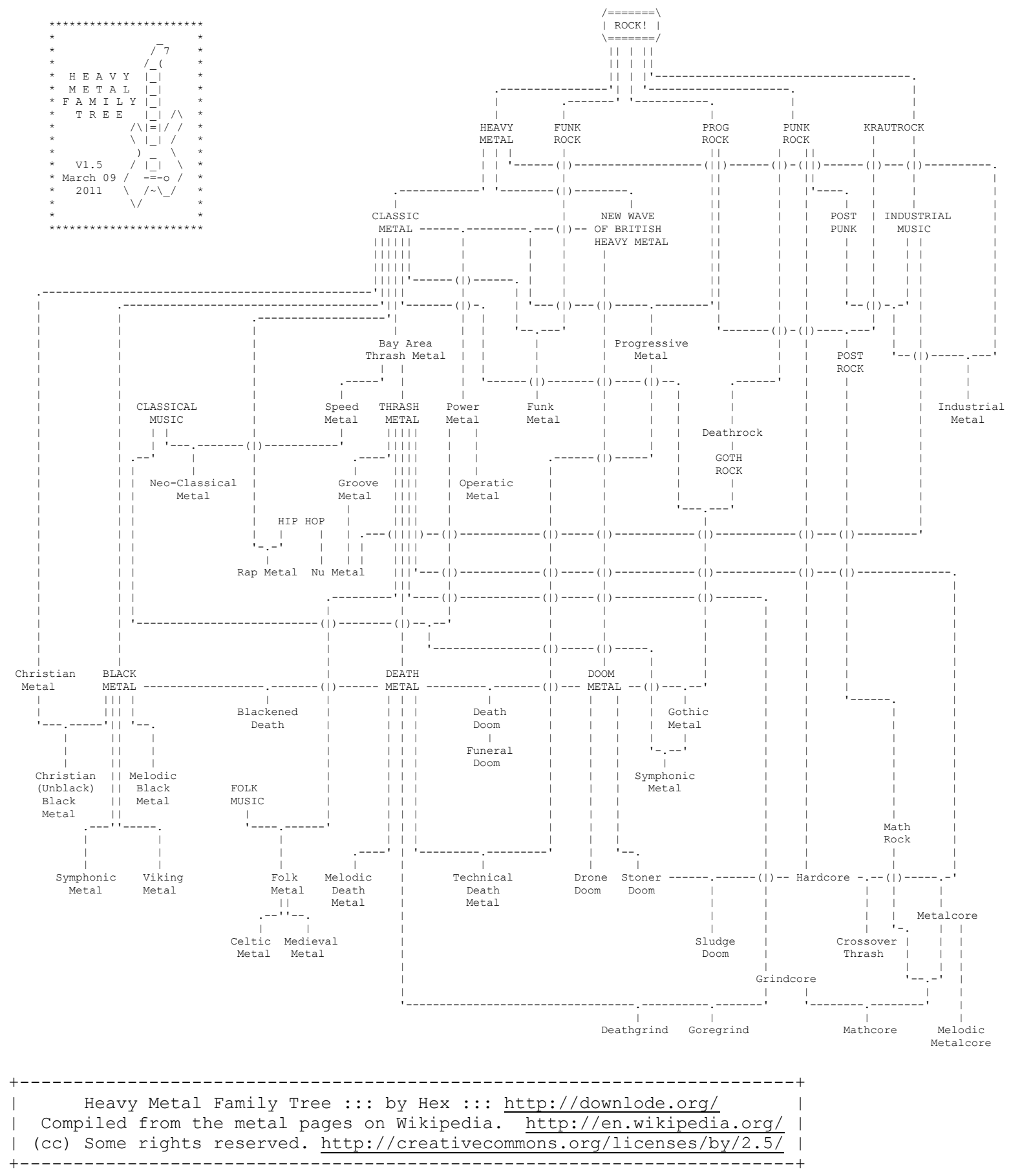

Figure 1

subcultural elements shared by both the artists and their fans. Going to a Death Metal show and a Black Metal show, for example, can be very different experiences, along not only sonic, but visual and textual dimensions as well. ${ }^{9}$

${ }^{9}$ Deena Weinstein, Heavy Metal: The Music and Its Culture, rev. ed. (Cambridge, Mass.: Da Capo Press, 2000): 6-8. 
How do the subgenres originate? It often begins with bands creating specialized niches, taking elements of the heavy metal "code" and emphasizing certain features to the exclusion of others. ${ }^{10}$ It could start with an emphasis on rhythm over melody, a new vocal technique, a new guitar sound, an avoidance of the traditional guitar solo, a slip towards atonality, and so forth. As other bands and fans close ranks around this new style, it can come to be seen as distinct from other styles and worthy of having a new label assigned to it. These subgenres stand at the peripheries of metal or at the intersection of metal and other genres of music, but retain enough of the traditional heavy metal code to remain within the family - to be considered an off-shoot rather than an entirely new genre.

A more difficult question, perhaps, is why these subgenres develop and why metal has so many compared to other types of popular music. A complete answer to this question is beyond the scope of this article, but briefly, here are a few ideas to consider. First, metal has always been about being the most "extreme" form of rock music: the loudest, most dangerous, most powerful, most frightening. Often, when new genres emerge, we're seeing a new generation of performers attempting to outdo the previous, by being faster, louder, "heavier," more technical and virtuosic. ${ }^{11}$ This is the reactionary development. We also see new genres created at the intersection of metal and other forms of music. Rap-metal or nu-metal, for instance, combines metal with rap, funk, and hip-hop musics. Industrial metal brings industrial music into the mix, hardcore brings punk rock, and ambient metal brings in ambient and electronic music. We also see mixing at the borders of metal genres themselves, creating fusions such as gothic metal, death-doom, ambient black metal and so forth.

Ronald Byrnside has noted that many styles of popular music go through a series of stages in their construction and eventual dissolution: formation, crystallization, and decay. ${ }^{12}$ This model is useful for looking at musical genres. In the formative stage, a new style detaches itself from its predecessor; in the crystallization phase, the new style establishes itself and the audience begins to recognize its boundaries; finally, the style becomes so predictable that both the composer/performer and the audience begin to lose interest, and so the style enters a state of decay.

Deena Weinstein, in her classic study on heavy metal, applies Byrnside's model but argues that rather than decaying, heavy metal has gone through a process of fragmentation, during which it has split into a great number of distinctive subgenres. While some of these may have fallen into a state of decay or been abandoned entirely, others are thriving to this day. Furthermore, the fragmentation continues, with new subgenres being created as metal develops and fuses with other styles of music. ${ }^{13}$

I would like to look closely at a few of these subgenres in order to give a sense of what distinguishes them and how they can be identified. There tends to be a continuum from wellestablished and accepted subgenres to more controversial ones. This aspect has become particularly interesting in the internet age, where information is created and propagated so

\footnotetext{
${ }_{11}^{10}$ For more discussion of this "code," see the first chapter of Weinstein's book.

${ }^{11}$ Albert Mudrian's book Death: The Improbable History of Death Metal and Grindcore has some convincing quotes to support this. For example, from Joseph Mascis of the band Deep Wound: "We wanted to play as fast as possible ... All we were concerned with, really, was playing faster and faster." ( $p$. 47).

${ }^{12}$ Ronald Byrnside, "The Formation of a Musical Style: Early Rock," in Contemporary Music and Cultures, ed. Charles Hamm, Bruno Nettl, and Ronald Byrnside (Englewood Cliffs, N.J.: Prentice-Hall, 1974).

${ }^{13}$ Weinstein, 7.
} 
quickly. It is fascinating, for example, to read the "talk" pages for Wikipedia articles on metal genres. Since anyone can create a page on Wikipedia, there is no need for any kind of consensus before a new term is added. Debate can quickly form in the talk pages, however, around the legitimacy and quality of an article. Discussion surrounding metal subgenres tends to concern the names and essential attributes of the style in question. As well, any subgenre term that appears on Wikipedia and survives the initial debate can quickly spread around the Web. This is the case even for highly controversial genres. In this way, influential web sites such as Wikipedia or Encyclopedia Metallum may have a hand in "creating" or defining genres themselves. $^{14}$

Following is an examination of the four principle "extreme" subgenres of metal: thrash metal, doom metal, death metal, and black metal. These are the main subgenres to emerge since the fragmentation of metal in the late 1970s and are, arguably, the most accepted and well-defined in the literature today. The history and principle characteristics of each of these four subgenres will be briefly described, with a list of representative recordings a library might want in its collection included as an appendix.

\section{THRASH METAL}

We can start with thrash metal because it was the first of the distinctive "extreme" metal genres - metal that was abrasive and difficult, and, at least initially, fell outside the popular metal sphere.

Thrash emerged on the US West Coast, principally in Los Angeles and the San Francisco Bay Area. It was in large part a reaction against the prevailing metal genre in Los Angeles at the time - the glam metal or hair metal scene - and its perceived commercialization, effeminacy, and lack of toughness. These flashy, theatrical acts with big hair, makeup, spandex, and headbands, epitomized by bands such as Motley Crue, WASP, and Twisted Sister, were vilified by a new generation of players listening to raunchier sounds coming out of England and continental Europe in the late 1970s. ${ }^{15}$ In a way, glam brought thrash into being, as without it, the thrashers would not have had a target to unite against. Many metal subgenres have been born in opposition like this.

Thrash took its cues from the so-called New Wave of British Heavy Metal, a movement in the late-70s English clubs that "toughened up" the sound of the 70s megabands like Black Sabbath, Led Zeppelin, and Judas Priest, increasing the tempo and incorporating elements from punk rock music. Thrash was about speed, power, trademark "crunchy" guitar riffs, and technical proficiency.

Three of the "Big Four" of thrash metal, Metallica, Megadeath, and Slayer, all came out of the west coast scene, starting out in either Los Angeles or the Bay area. The other, Anthrax, originated in New York City. A third scene in Germany developed slightly later and produced bands such as Sodom, Kreator and Destruction. All of the scenes, as with most nascent metal genres, were built around small, independent record stores that were importing the latest, most "hardcore" music from around North America and Europe. Also important in giving a sense of identity and organization to these scenes were tape-trading networks, underground magazines and, eventually, college radio play. While, at the beginning, getting signed to a label and

\footnotetext{
${ }^{14}$ See, for example, the Talk Page on "Symphonic Metal": http://en.wikipedia.org/wiki/Talk:Symphonic metal (accessed March 30, 2011).

${ }^{15}$ Rick Ernst, Get Thrashed: The Story of Thrash Metal, DVD, (New York: Lightyear Entertainment, 2008).
} 
releasing commercial LPs was a distant dream to these bands, they could all easily and cheaply make cassette tape demos. These were then distributed among fans locally and even nationally and helped create rabid and ready fans for many bands. ${ }^{16}$

As some of the thrash bands began to play more concerts, gaining visibility and a solid fan base, record labels sprang up to release their music. The two major early thrash labels in the US were Metalblade Records on the West Coast and Megaforce Records in New York. These two labels released many of the early thrash albums by the "Big Four," as well as other influential thrash bands such as Testament, Vio-lence, Overkill, Anvil, and Exciter. There were several other young labels releasing thrash metal in the early 80 s, including Combat Records and Noise Records.

The principal characteristics of thrash metal include fast tempos, "shredding" guitar solos, and complex, often palm-muted rhythm guitar riffs. An earlier prototype genre that preceded thrash, exemplified by the band Motorhead, is sometimes called "speed metal" due to its increased tempo. Thrash picked things up another notch and rarely relented-it was not until the 90s that thrash bands such as Metallica began incorporating anything that could be termed a "power ballad". There is a physicality and endurance required to keep up such tempos throughout the course of a concert, particularly for drummers, who are often equipped with double kick drums to maintain the fast, pounding pace of thrash songs.

A "riff" in blues, rock, and metal is a repeated chord progression on the guitar - usually doubled by the bass - lasting a few bars and sometimes transposed up or down through the course of a song. These chords usually consist of only the root and the fifth and/or octave played on the lower stings of the guitar, omitting the third and any upper extensions, which makes the tonality vague and allows for a greater amount of chromaticism. In hard rock and metal music, these are called "power chords". Heavy metal songwriters became fond of power chord riffs built on minor seconds, minor thirds, and diminished fifths in particular -intervals that are often seen as having a tense or "evil" sound.

The riffs of early metal bands such as Black Sabbath were relatively simple and often consisted of only a few chords. Thrash bands were building longer, more varied, and more complex riffs and playing them at blistering speeds and extreme volume. Guitarists often used a technique called palm-muting, in which the player uses a part of their picking hand on the bridge of the instrument to mute, or dampen, the sound of distorted power chords. Alternating muted and unmuted chords allowed guitarists to create a kind of "chugging" sound that is characteristic of thrash metal and, later, death metal.

Although the rhythm guitar/bass riffs give thrash its distinctive sound to a large degree, lead guitar solos are another important feature, more so than in any of the other extreme metal subgenres. "Shredding" involves a collection of guitar techniques that are generally performed at a high speed and volume. These include sweep and tremolo picking, finger-tapping and trills, and liberal use of the whammy bar for "dive bombs" and other such effects. ${ }^{17}$ All serve to increase the speed and energy of the guitar solos that are essential to most thrash metal songs. Excellent examples of this style can be heard in the dueling guitar solos of Slayer's Kerry King and Jeff Hanneman.

\footnotetext{
16 Ibid.

17 See the Wikipedia article on "Shred Guitar" for descriptions of these and other techniques: http://en.wikipedia.org/wiki/Shred guitar (accessed March 30, 2011).
} 
The vocal style and lyrical content of thrash metal are fairly diverse and are not defining elements. Vocals can range from high, soaring falsettos to low, aggressive shouting and topics run from violence to politics to Armageddon to Satanism. Unlike death, black and doom, thrash does not have as consistent a set of themes or method of vocal delivery.

As thrash developed through the later 80 s, the 90 s, and into the twenty-first century, the "Big Four" came to be its most lasting, dedicated, and popular practitioners. Metallica in particular built an enormous following and has been one of the most successful rock bands of any genre. Many of the other thrash bands - along with all forms of metal-suffered in the 90s with the rise of grunge and the Seattle alternative rock scene. Further decline was caused by the emergence of so-called nu-metal in the late 90s. Bands playing this style; such as Limp Bizkit, Korn, System of a Down, and Slipknot; were incorporating grunge, hip hop, electronics, and DJs/turntablists into their fundamentally metal music. ${ }^{18}$

After a decade of marginalization, there has been something of a resurgence of thrash in recent years. ${ }^{19}$ Many bands in Europe and America have been looking back to early albums from the likes of Slayer and Metallica and creating a throwback style that looks and sounds similar to 80s thrash. These include young bands such as The Haunted, Carnal Forge, Dew-Scented, Municipal Waste, Bonded by Blood, and Merciless Death. Elements of thrash also live on in death metal, the extreme metal subgenre that followed it and incorporated many of its devices.

\section{DOOM METAL}

While all metal owes a heavy debt to Black Sabbath, its true progeny - the subgenre that has most carefully extracted and refined that band's distinctive characteristics - is doom metal. Guitarist Tony lommi's thick, heavy riffs, the band's medium-slow tempos, and Ozzy Osbourne's lyrics of despair and paranoia on albums such as Black Sabbath and Paranoid are the essence of doom.

A glacial style of metal, doom is characterized primarily by these relatively slow, plodding tempos - which contrast strongly with those of speed/thrash metal, the other metal subgenre developing in the late70s and early 80 s - and dense textures. These thick, heavy textures are often achieved with a combination of heavy distortion and down-tuned guitars - guitars with their strings dropped below standard tuning to achieve lower frequencies than would normally be available. Doom can be seen as a somewhat "neoclassical" metal genre and its development a reaction against prevailing trends towards speed and technical prowess. Indeed, some of the later subgenres of doom return to the very roots of Sabbath itself, as sludge metal and stoner metal take some cues from the psychedelic and blues rock of the sixties. In the other direction, doom is also one of the more experimental and pioneering areas of metal, with drone doom bands experimenting with minimalism, noise, electronics, and more ambient textures.

Lyrically, doom metal tends to be more introspective than other major metal subgenres. It lacks the aggression and violence of thrash, death, or black metal and focuses on more existential concerns - anxiety, despair, suffering, fear, death. Some doom bands display an interest in the fantastic and mythological as well, with songs about wizards, warriors and fantastical creatures. Perhaps, again, they are taking their cue from the more psychedelic hard rock and metal bands of the early 70s, such as Led Zeppelin and Black Sabbath, or from the nascent genre of Viking metal. Other themes include ancient civilizations; paganism, witchcraft, and the occult (another

\footnotetext{
${ }^{18}$ See Jeff Kitts and Brad Tolinski, Guitar World Presents Nu-Metal (Milwaukee, WI: Hal Leonard, 2002).

${ }^{19}$ Ernst.
} 
obsession of metal precursors such as Black Sabbath and Led Zeppelin); or drugs and psychedelia, as in the case of sludge/stoner metal.

Doom's early development can be traced through the late 70 s and early 80 s with Sabbathinfluenced bands such as Pentagram, St. Vitus, Trouble, Pagan Altar, Candlemass, and Witchfinder General. ${ }^{20}$ These bands remained outside of the popular metal/hard rock scene of the time, which was focused on glam, power metal, and, later, speed/thrash metal, and developed their own underground following. Some of these bands, such as Pentagram, which formed in the early 70 s but did not release a commercial full-length recording until 1985 , toiled in obscurity for many years. Nonetheless, these early doom bands forged a distinct and recognizable style of metal. Though the precise origin of the term is debated, "doom metal" was in common use by the mid-80s and was popularized with the 1986 release of Candlemass' Epicus Doomicus Metallicus. ${ }^{21}$

After a period of decline, due to the dominance of other subgenres, there was a resurgence of doom metal in the 90 s when many bands attempted to merge the prevailing metal subgenre, death metal, with doom characteristics. By slowing death metal down and moving away somewhat from its morbid obsessions with violence and gore, these bands pioneered a distinct hybrid genre often referred to as death/doom, ${ }^{22}$ which further developed into gothic metal. This latter subgenre, though it can be seen as distinct or as a fusion genre of heavy metal and Goth rock, has its roots in doom metal. The subgenre's three most influential bands, My Dying Bride, Anathema, and Paradise Lost, all began in a doom or death/doom style and gradually developed, taking on exterior influences. ${ }^{23}$ Gothic metal tends to have a colder, more romantic character, is more complex and eclectic compositionally, and often features tighter arrangements and higher production values than other metal subgenres. The frequent use of keyboards and operatic female vocals brings gothic music much of its distinctive character.

\section{Death Metal}

My main goal was to bash out the most brutal riffs ever, with the most brutal guitar sound ever. - Chuck Schuldiner of Death ${ }^{24}$

We were trying to be the heaviest thing on the face of the planet. We wanted to piss people off and send everybody home. - Jeff Beccera of Possessed ${ }^{25}$

Death metal has a history that is somewhat more complex than that of thrash or doom. Once again, however, it emerged among a new generation of metalheads wanting to play faster, louder, and more menacingly than anyone else. Death metal arose out of a confluence of three primary influences: thrash metal, developing on the US West Coast; the darkest and heaviest of European bands, particularly Venom and Celtic Frost; and "hardcore" punk rock and "grindcore" coming out of New York and the UK. ${ }^{26}$ The genre emerged principally in Florida, with another

20 "Doom Metal," Allmusic, accessed April 1, 2011, http://www.allmusic.com/explore/style/doom-metald11956.

${ }^{21}$ Garry Sharpe-Young, A-Z of Doom \& Gothic Metal (London: Cherry Red, 2003).

22 "Death/doom," Wikipedia, accessed April 1, 2011, http://en.wikipedia.org/wiki/Death/doom.

${ }^{23}$ Sharpe-Young.

${ }^{24}$ Quoted in Albert Mudrian, Choosing Death: The Improbable History of Death Metal \& Grindcore (Port Townsend, WA: Feral House, 2004), 67.

${ }^{25}$ Ibid., 70.

${ }^{26}$ Ibid., 25-65. 
major scene developing almost simultaneously in Sweden. ${ }^{27}$

The early Florida bands, mostly based in and around Tampa, included several that defined the genre in the 80s: Possessed, Death, Amon, Executioner, and Morbid Angel. Possessed and Death (originally called Mantas) both formed in 1983 out of groups of high school friends. Possessed's vocalist, Jeff Beccera, is most often credited with first using the distinctive, guttural "death growl" vocal style that came to be a defining characteristic of the genre. His band may also have been responsible for the term "death metal" itself, this being the title of the last track on their debut album, Seven Churches (1984). ${ }^{28}$

Chuck Schuldiner of Death is considered to be one of the early architects of death metal, defining the sound and bringing together some of the best early players in the genre from both the east and west coasts. After producing several influential demos, Death released their first full-length album, Scream Bloody Gore, in 1987. Released on Combat Records, this debut was called "death metal at its utter most extreme, brutal, raw and offensive - the kind that separates true death metallers from countless trend-following wimps." ${ }^{29}$ Death, with various line-up changes, would continue playing and releasing well-regarded albums until Schuldiner's death in 2001.

Morbid Angel, led by guitarist Trey Azagthoth, would develop into the first truly virtuosic death metal group. They formed in the early 80 s, and while they recorded their first demo, Abominations of Desolation, in 1987, they really honed their sound practicing around the clock in a rented house in Charlotte, North Carolina, the following year. The crucial component of the band was drummer Pete Sandoval, who joined in ' 88 and perfected the high-speed blast beats essential to the death metal sound. ${ }^{30}$ Morbid Angel released their first albums, both classics of the genre, in 1989 (Altars of Madness) and 1991 (Blessed are the Sick) and have continued to record into the twenty-first century.

Death metal pushed many of the characteristics of thrash metal a step further: faster, darker, more complex, more distortion, more unconventional vocal styles. The last is the most easily distinguishable element of death metal. Vocalists sing in a deep, guttural growl — often referred to as the "death growl" or as "Cookie Monster" ${ }^{31}$ vocals - which is largely unintelligible. The death growl blends well with the down-tuned, heavily distorted sound used by death metal guitarists.

In terms of their composition, death metal songs tend to be extremely fast and complex, with frequent changes in meter and tempo. One technique used to create a punishing wall of sound in sections is the "blast beat", which has been described as follows: "The blast-beat generally comprises a repeated, sixteenth-note figure played at a very fast tempo, and divided uniformly among the kick drum, snare and ride, crash, or hi-hat cymbal." ${ }^{32}$ Death metal drummers often utilize a double kick drum set-up, so as to be able to maintain the speed necessary to keep up with the guitars and create more punishing blast beats.

\footnotetext{
${ }^{27}$ For a detailed history of this scene see Daniel Ekeroth, Swedish Death Metal (Brooklyn, NY: Bazillion Points Books, 2008).

${ }^{28}$ Mundrian, p. 70.

${ }^{29}$ Quoted in Mudrain, p. 75.

${ }^{30}$ Mudrian, p. 82-86.

31 "Death Growl," Wikipedia, accessed April 1, 2011, http://en.wikipedia.org/wiki/Death growl.

32 "Blast Beat," Wikipedia, accessed April 2, 2011, http://en.wikipedia.org/wiki/Blast beat.
} 
While the imagery and lyrical content of heavy metal has been on the dark side from the beginning, it certainly took its most gruesome turn with the emergence of death metal. The band names themselves can give a good sense of this: Severe Torture, Massacre, Napalm Death, Atrocity, etc. These names are representative of the preoccupations of the subgenre: gore; misanthropy; extremely violent acts such as torture, rape, cannibalism, mutilation; and wanton destruction or Armageddon. The album art and band logos often have a slasher-film or apocalyptic aesthetic. Unfortunately - or fortunately, depending on one's perspective - death metal lyrics are often incomprehensible, due to the vocal style. One must often turn to the liner notes to make sense of them. Here is a representative example from the band Severe Torture:

Spiritual obscenity

Creates my desire to kill

Victims lay down screaming

Ready to be butchered

I open their eyes

For them to see

How I start eating

Of their flesh

Mental sickness

Overrules my sympathy

Misanthropic carnage

Molesting each and every part

Mutilating their souls

Until they'll fear the light

Misanthropic carnage

Slaughtering humanity

With their useless, fucked up minds

They'll crawl for me and die!!!

Fucking the wounds

Of the half rotten cadavers

With sickened disgust

Of what they believe

Sexual fulfillment

As I cum in their lying mouths ${ }^{33}$

As death metal developed into the twenty-first century, it began-like the metal genre as a whole - to fragment into specialized styles and fuse with other types of music. A few of the more prominent styles to emerge are Melodic Death Metal, Brutal Death Metal, and Technical Death Metal. The former, also referred to as the "Gothenburg sound" due to its birthplace, incorporated a more melodic vocal style and a more traditional harmonic base into the death metal sound. The "brutal" and "technical" styles represent opposing perspectives on how to approach writing and playing death metal. Brutal death metal is somewhat rougher, with more basic riffs and song structures, while technical death metal focuses on more complex, progressive arrangements, with many virtuosic changes in riffs, tempos, time signatures, and dynamics.

${ }^{33}$ Severe Torture, "Misanthropic Carnage," in Misanthropic Carnage (Netherlands: Hammerheart Records, 2002). 


\section{BLACK METAL}

Black metal is one of the more difficult metal subgenres to define. The principal reason for this is that it is often connected as much with a particular ideology or movement than with specific musical characteristics. Associated with Satanism almost from the start, black metal is sometimes understood as being any type of metal that is overtly Satanist, thus the "black" label and long-time association with the black arts. However, when one examines this association more closely, away from the hyperbole of the media, ${ }^{34}$ there are few supposedly black metal bands that are practicing Satanists to any significant degree. More often, their use of Satanism is a kind of theater, designed to provoke the establishment, gain notoriety, and with that notoriety more popularity with disenfranchised youths and metal fans in Christian nations. This can be seen with early black metal bands such as Venom and Mercyful Fate, whose elaborate stage shows, costumes, and album covers often included enactments of ritual sacrifice and other practices associated with the dark arts, but who now readily admit that their flirtation with Satanism was shallow at best. ${ }^{35}$

The other problem with the Satanist label is that many bands that did have a strong ideology behind their music were not Satanists but rather endorsed some form of paganism/heathenism or romantic nationalism. This was especially the case with Scandinavian black metal, with bands like Bathory and Burzum espousing pre-Christian ideologies connected to their Nordic roots. For this reason, it is useful to categorize the ideology of black metal more broadly as antiChristian, rather than labeling it Satanist, pagan, or with any other category. This is not to say that there are no overtly Satanist black metal groups; the band Ulver, for example, and Ishan, the vocalist for the influential band Emperor, do proclaim themselves practicing Sataniststhough their fairly mature ideologies do not fit popular conceptions. ${ }^{36}$ Such groups, however, are very much in the minority.

While being anti-Christian might be a necessary condition for music to be called black metal, it is clearly not sufficient. The history of metal has been rife with anti-Christian sentiment almost from the beginning, ${ }^{37}$ and this attitude pervades all subgenres to some extent. The anti-Christian outlook must be combined with specific musical characteristics to give the genre identity and definition. While black metal cannot be as easily defined by a few distinctive techniques, as can other subgenres such as doom, thrash, or death metal, there are some broad stylistic trends.

Black metal is one of the latest in a series of increasingly "extreme" genres of metal, extremity here usually defined by increasing levels of speed, volume, and general abrasiveness. Thus, black metal tends to be faster, louder, rougher, and more menacing than other forms of metal. These are all ambiguous and relative terms, of course, but there are some more specific stylistic conventions we can identify: black metal tends more towards the higher frequencies than the lower, in terms of both vocal and guitar styles. Rather than the thundering, palm-muted, and bass-heavy power chords that characterize thrash and death metal, black metal often features sheets of thin, trebly guitar and single-note lines. As well, rather than gravelly, deep-throated or clean, soaring vocals, black metal singers grunt, scream, wail, and are generally menacing and

\footnotetext{
${ }^{34}$ See Michael Moynihan and Didrick Soderlind, Lords of Chaos: The Bloody Rise of the Satanic Metal Underground, New ed. (Port Townsend, WA: Feral House, 1998): 99-102.

${ }^{35}$ Det Svarte Alvor, video aired on Norwegian television NRK TV2 in 1994.

${ }^{36}$ Ibid.

${ }^{37}$ See, for example, Black Sabbath's self-title debut, released in 1970.
} 
unintelligible in their shrill cries. In classic Norwegian black metal, the guitarists usually employ tremolo picking, where each single note is repeated rapidly to create long, sustained, and piercing guitar lines.

Low production values are another characteristic of black metal. While at the beginning, with the early recordings of bands like Venom and Bathory and again in the early development of the Norwegian scene, this was out of necessity - run-down demo studios or home recording was all that was available to them - it was also intentional at times. By way of example, some of the recordings of Mayhem, Burzum, and Darkthrone were made with equipment completely inappropriate to the task; for instance, use of a pair of headphones as a microphone to record vocal tracks. ${ }^{38}$ This thin, lo-fi sound helped maintain black metal's status as a raw, underground scene. Always averse to commercialism of any kind, black metal groups - particularly those from the Norwegian scene - have been careful to maintain their integrity and credibility, avoiding any accusations of selling out or pandering to an audience. This is part of black metal's reaction to the codification and commercialization of the previously most extreme metal genre, death metal, in the late 80 s and early 90 s. $^{39}$

Not surprisingly, black metal lyrics are often concerned with Satan, satanic ritual, and the occult. These themes can be found in everything from the earliest recording of Venom, Welcome to Hell, to contemporary superstar black metal bands like Cradle of Filth, leaving little question as to why this genre of music came to be associated with devil worship. But beyond this, there are several other important themes to be found in the lyrics and song titles of black metal:

misanthropy, Norse mythology, nature worship, folklore, fantasy, Nietszchian will to power, and, occasionally, racism. Because black metal vocals are often indecipherable (not to mention that much influential black metal is sung in Norwegian), the content of the lyrics often has less impact than the nature of their delivery. While black metal does often have an ideology behind it-a worldview more sophisticated than the sex, drugs, and rock \& roll anti-establishment position of most other forms of rock and metal - it is not overtly political, as are punk rock and hardcore to a degree. Some black metal bands claim they are not trying to incite the listeners to any kind of political action; instead, their music is often intended to communicate on more of a spiritual level. ${ }^{40}$

The history of black metal can best be told as a sequence of three waves: the precursors, the Norwegian scene, and the later popularization and commercialization of the genre. But prior to the real musical precursors of the genre, there are a few bands that deserve mention for the earliest use of satanic ritual, face paint, and other characteristics that have become associated with black metal. Two rock bands in the late 60 s and early 70 s, Coven and Black Widow, under the influence of Anton LaVey and his Church of Satan, created elaborate stage shows featuring black masses and other occult rituals. ${ }^{41}$ Though these bands were playing a kind of progressive rock and any musical influence on black metal would be extremely tangential, the satanic and occult lyrics and imagery they employed would be influential on bands that would develop the genre, such as King Diamond of Mercyful Fate. Other performers, such as Alice Cooper and Kiss would pioneer the use of face paint in heavy metal. Though their use was somewhat more colorful, garish and theatrical, it was a precedent for the black and white "corpse paint" that

\footnotetext{
38 "The Count Speaks ...," Terrorizer 28, March 1996.

${ }^{39}$ Moynihan and Soderlind, 31-32.

${ }^{40}$ Det Svarte Alvor.

${ }^{41}$ Rockworld TV, Murder Music: A History of Black Metal, originally aired April 13, 2007, available at http://www.rockworld.tv/MurderMusicPlayer.html (accessed April 2, 2011).
} 
many Norwegian black metal bands and their fans would employ in the $90 \mathrm{~s}^{42}$ Thus there are continua along several lines that lead from some of these early rock and metal bands through to the black metal pioneers, and much of the ideology, imagery, and performance techniques were there to be appropriated by black metal artists in the later 80 s and $90 \mathrm{~s}$.

The musical precursors to black metal are a collection of relatively unconnected and geographically dispersed groups that laid some of the foundations and broke some of the boundaries that allowed the genre to develop. These developments are most often traced to Venom in England, Celtic Frost in Switzerland, and Bathory in Sweden, as these are the groups frequently cited as an influence by those who would establish the genre. ${ }^{43}$ With their 1982 album Black Metal, Venom gave the genre its name. Though they were playing a more raw and extreme type of speed or thrash metal at this time, it was noticeably distinct from many contemporary thrash bands, and when asked in interviews what this music should be called, they allowed that "black metal" was an appropriate enough label. ${ }^{44}$ Though Venom had no particular ideology behind their music and, at heart, they were really a sex, drugs, and rock \& roll type of band, like many other metal acts of the 80 s, with songs about drinking, partying, women, and rock \& roll, there is an increasing amount of blasphemous and satanic lyrical content and imagery in their work. In their early albums Welcome To Hell and Black Metal, Venom set another black metal tradition by choosing a distinctive stage name for each band member. This is a tradition that was followed by many black metal bands well into the 90 s, and many of the major figures in black metal are principally known by these noms de guerre: Euronomous, Count Grishnakh, Nocturno Culto, Abbath, Ihsahn, Faust, etc. Venom's influence extends beyond just black metal, as many players in the thrash, death metal, grindcore and other developing styles of extreme metal have pointed back to Venom as a turning point in the development of many of the most brutal styles of heavy metal.

Like Venom, Celtic Frost produced music of an increased level of rawness and "extremity" and was influential to a variety of upstart bands that would help develop not only black metal, but death metal and grindcore as well. But the band that would be most influential and is the earliest embodiment of many of the distinctive characteristics of black metal is the Swedish band Bathory, which was essentially a one-man studio project of the enigmatic guitarist Quorthorn. The satanic lyrics, Viking imagery, low-fi production values and raw, guttural vocal style of Bathory would be an inspiration to many in the 80s metal underground. Many Norwegian bands, including Mayhem and Burzum, have cited Bathory as a primary influence. This is in large part due to Bathory's glorification of Norse mythology in their lyrics and album art; these themes are most clearly stated in the so-called "Viking Trilogy", beginning with the 1988 album Blood, Fire, Death and followed by Hammerheart and Twilight of the Gods.

The origin of black metal as we know it today was in Norway in the late 80s and early 90s. Here, a number of bands influenced by Venom, Bathory, Celtic Frost, as well as by punk and progressive rock music, and reacting to what they saw as the increasing commercialism and decadence in Swedish death metal music, built a scene sympathetic to the most extreme music and codified the conventions of the black metal genre. Led by Mayhem in the late 80 s, and soon followed by bands such as Darkthrone, Burzum, Emperor, Ulver, and Immortal, a youthful extreme metal scene, built on word of mouth, tape trading, underground fanzines, chance

\footnotetext{
${ }^{42}$ For and excellent photographic display of "corpse paint", see Peter Beste and Johan Kugelberg, True Norwegian Black Metal: We Turn in the Night Consumed by Fire (Brooklyn, New York: Vice Books, 2008). ${ }_{43}^{4} \mathrm{Pal}$ Asadal and Martin Ledang, Once Upon a Time in Norway, DVD ([UK]: Plastic Head, 2008).

${ }^{44}$ See interview with Venom's Cronos in Bill Zebub, Black Metal: A Documentary, DVD ([USA]: Bill Zebub Productions, 2007).
} 
meetings at metal shows, and other pre-internet forms of communication, began to form, primarily in and around the city of Oslo. With ideological and musical leaders Oystein "Euronomous" Aarseth and Varg "Count Grishnakh" Vikernes and an inner circle of initiates formed at the record store Helvete ("Hell"), the bands in this scene strove to create the most extreme metal possible. ${ }^{45}$

Along with the unprecedentedly vicious music itself, there were a number of controversial events in the early 90 s that put black metal in the media spotlight and likely led, to some degree, to its rise in popularity. These included church burnings, grave desecration, suicide, and murder, and while perpetrated by only a small minority of the black metal community, they have helped to shape the genre and give it its individual identity, for both the public and the members of the scene itself. These events form a distinct and powerful origin story for the genre and are to some degree the reason why the Norwegian scene is such an essential part of the narrative of black metal history. ${ }^{46}$

In the later 90 s and early 2000 s, some bands playing in the black metal style raised the quality of production and marketing and achieved a level of success and popularity that was likely never anticipated (or desired) by the subgenre's originators. Dimmu Borgir, from Norway, and particularly Cradle of Filth, from England, created a somewhat more accessible and marketable form of black metal that their labels and promoters were able to capitalize on for substantial record sales and concert tours. Not surprisingly, as this is a form of music that prides itself on an outsider and underground approach, many black metal fans have accused bands such as these as being "sell-outs" or not "True Norwegian Black Metal." 47

As with other types of metal, black metal has splintered into a number of subgenres and styles, including fusions with other genres and types of music. Some bands, in searching for their roots, have returned to what is often called Viking metal, a type of black metal that uses Norse mythology as its inspiration and lyrical subject matter. Others have incorporated old folk songs and created the unlikely genre of folk black metal. The influential black metal band Ulver, for example, frequently includes acoustic interludes in their songs and with their second full-length, Kveldssanger, ${ }^{48}$ they created an entire album of acoustic string music based on Norwegian folklore. Bands such as Emperor have created a much more complex, lyrical, and orchestral type of black metal that is often described as symphonic black metal. ${ }^{49}$ On their second album, Anthems to the Welkin at Dusk (1997), Emperor created elaborate, highly orchestrated compositions using layered guitars, keyboards, and dynamic, evolving compositions. Emperor initiated a type of black metal that cast off the low production values of early bands such as Mayhem and Darkthrone and embraced advanced studio techniques. On the fringes of the genre we can find black metal fusing with other styles of metal, such as doom metal (black doom) and death metal (blackened death metal), as well with musical genres outside of metal, including dark ambient music (ambient black metal). Burzum can be seen as a pioneer in the creation of the latter genre, as aspects of dark-tinged electronica can be found on early recordings, especially the 1996 album Filosofem. Varg Vikernes, the man behind Burzum, turned entirely to electronic music after his incarceration for murder in the mid-90s, releasing

\footnotetext{
${ }^{45}$ Moynihan and Soderlind, p. 71-75.

${ }^{46}$ See Moynihan and Soderlind for a detailed history of these events.

${ }^{47}$ See, for example, message board topics such as "Black Metal 'Sellouts': Dimmu Borgir vs. Cradle of Filth," http://www.metalstorm.net/forum/topic.php?topic id=1562 (accessed April 2, 2011).

${ }_{48}$ Ulver, Kveldssanger ([Norway]: Head Not Found, 1996).

49 "Symphonic Black Metal," Allmusic, accessed April 2, 2011, http://www.allmusic.com/explore/style/symphonic-black-metal-d11957.
} 
several albums in this style under the Burzum name - though this may have been due more to necessity than choice, with his musical options in prison being somewhat limited.

It is unfortunate that black metal music has often been overshadowed by the violence and criminal exploits of some of its high-profile practitioners. Within the genre can be found some of the purest, rawest, and most powerful metal made in the last two decades, as well as the most beautiful, if one opens their ear to the music.

\section{Cataloguing Metal}

Unfortunately, as librarians - and especially as cataloguers - we are often forced to jam things into generic boxes. Traditional subject cataloguing and classification do not allow for the refined categories that we might like to utilize with a complex musical genre like heavy metal. So, within the Library of Congress Subject Headings (LCSH), what do we have to work with?

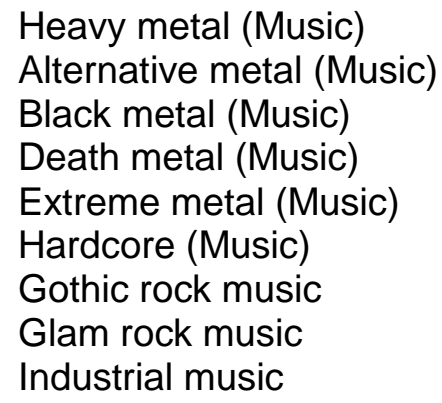

Though not terrible, this leaves a lot to be desired. To capture certain genres, a combination of headings is required. For example, for gothic metal one could use "Heavy metal (Music)" and "Gothic rock music"; similar combinations could be used for industrial metal or glam metal. But using multiple headings to capture one concept is not ideal. These subject headings are incapable of capturing many of the finer and well-established genres, however, and something more is needed.

Form/genre headings for music, which capture what an item is, rather than what it is about, are currently being prepared by the Music Genre/Form/Medium Group, a collaboration between the Library of Congress and the Music Library Association. ${ }^{50}$ These headings would be applied separately from topical subject headings and would go in the MARC 655 field. There was a call for genre submissions from interested parties, and at York we contributed many of the most established metal subgenres. Whether or not these will be accepted is not clear at this point, as this is a work in progress and a finalized list has not yet been prepared. Form/genre headings would allow a greater amount of granularity and would also better represent sound recordings, which are manifestations of a particular genre, not commentaries on them.

Until form/genre headings for music are made available, there are a couple of options for adding more specificity to heavy metal materials. Individual institutions could create a set of genre terms to use in a locally defined field (MARC 59X or 69X). This would allow a lot more freedom in adding multiple and highly specific subgenre terms than LCSH does, though at the possible sacrifice of control, cross-references, and compatibility with other institutions' records.

\footnotetext{
${ }^{50}$ See "Genre/Form Headings for Musical Works," http://www.loc.gov/catdir/cpso/genremusic.html (accessed April 3, 2011).
} 
The other option, which results in the same benefits and drawbacks, is to use a general MARC 500 field note. When dealing with sound recordings, AACR2 allows for a note detailing the "Nature or artistic form and medium of performance" (6.7B1) when this is not apparent from the rest of the description. This is the option we chose to use at York, which saved us from having to formally designate a local field dedicated to genre terms.

Both options require a cataloguer who has some experience with metal subgenres or, lacking that, one who is willing to spend additional time doing research into individual groups and performers. Hopefully, the preceding article will inspire such an interest in open-minded librarians, or at least help the closet metalheads around us to come out into the open and engage in such projects. 


\section{APPENDIX: ReCOMmEnded RECORDINGS}

THRASH MetaL

\begin{tabular}{|l|l|l|l|}
\hline Annihilator & Alice in Hell & 1989 & Roadrunner \\
\hline Anthrax & Among the Living & 1987 & Megaforce \\
\hline Artillery & By Inheritance & 1990 & Roadracer \\
\hline D.R.I. & Crossover & 1987 & Metal Blade \\
\hline Death Angel & Act III & 1990 & Geffen \\
\hline Destruction & Eternal Devastation & 1986 & Metal Blade \\
\hline Exodus & Bonded By Blood & 1985 & Combat \\
\hline Kreator & Pleasure to Kill & 1986 & Noise \\
\hline Megadeath & Rust In Peace & 1990 & Capitol \\
\hline Metallica & Kill 'Em All & 1983 & Elektra \\
\hline Nuclear Assault & Game Over & 1987 & Combat \\
\hline Overkill & The Years of Decay & 1989 & Megaforce \\
\hline Pantera & Cowboys From Hell & 1990 & Atlantic \\
\hline Sepultura & Beneath the Remains & 1989 & Roadrunner \\
\hline Slayer & Reign in Blood & 1986 & American \\
\hline Sodom & Agent Orange & 1989 & Roadracer \\
\hline Testament & The Legacy & 1987 & Atlantic \\
\hline Vio-lence & Eternal Nightmare & 1988 & Mechanic \\
\hline Voivod & Nothingface & 1989 & Mechanic \\
\hline
\end{tabular}

\section{DOOM Metal}

\begin{tabular}{|l|l|l|l|}
\hline Anethema & Serenades & 1994 & Peaceville \\
\hline Burning Witch & Crippled Lucifer & 1998 & Southern Lord \\
\hline Candlemass & $\begin{array}{l}\text { Epicus Doomicus } \\
\text { Metallicus }\end{array}$ & 1986 & Leviathan \\
\hline Cathedral & Forest of Equilibrium & 1991 & Combat \\
\hline Earth & Earth 2 & 1993 & Sub Pop \\
\hline Electric Wizard & Come My Fanatics ... & 1996 & Music Cartel \\
\hline Eyehategod & Take as Needed For Pain & 1993 & Century Media \\
\hline Khanate & Khanate & 2001 & Southern Lord \\
\hline Melvins, The & Gluey Porch Treatments & 1987 & Boner \\
\hline Obsessed, The & The Church Within & 1994 & Columbia \\
\hline Paradise Lost & Gothic & 1991 & Peaceville \\
\hline Pentagram & Day of Reckoning & 1987 & Peaceville \\
\hline Sleep & Jerusalem & 1999 & Music Cartel \\
\hline St. Vitus & Born Too Late & 1986 & SST \\
\hline Sunn O))) & Black One & 2005 & Southern Lord \\
\hline & & & Avantgarde \\
Thergothon & Stream From the Heavens & 1994 & Music \\
\hline Thorr's Hammer & Dommedagsnatt & 1996 & Southern Lord \\
\hline Trouble & Psalm 9 & 1984 & Metal Blade \\
\hline Witchfinder General & Death Penalty & 1982 & Heavy Metal \\
\hline
\end{tabular}




\section{Death Metal}

\begin{tabular}{|l|l|l|l|}
\hline At the Gates & Slaughter of the Soul & 1995 & Earache \\
\hline Autopsy & Severed Survival & 1989 & Peaceville \\
\hline Cryptopsy & None So Vile & 1996 & Wrong Again \\
\hline Cynic & Focus & 1993 & Roadrunner \\
\hline Dark Tranquility & The Gallery & 1995 & Osmose \\
\hline Death & Scream Bloody Gore & 1987 & Combat \\
\hline Deicide & Deicide & 1990 & Roadrunner \\
\hline Dismember & $\begin{array}{l}\text { Like An Ever Flowing } \\
\text { Stream }\end{array}$ & 1991 & Nuclear Blast \\
\hline Entombed & Left Hand Path & 1990 & Earache \\
\hline Grave & Into the Grave & 1991 & Century Media \\
\hline In Flames & The Jester Race & 1995 & Nuclear Blast \\
\hline Morbid Angel & Blessed are the Sick & 1991 & Combat \\
\hline Napalm Death & Scum & 1987 & Earache \\
\hline Possessed & Seven Churches & 1985 & Relativity \\
\hline Repulsion & Horrified & 1989 & Necrosis \\
\hline Unleashed & Where No Life Dwells & 1991 & Century Media \\
\hline
\end{tabular}

\section{Black Metal}

\begin{tabular}{|l|l|l|l|}
\hline Bathory & Blood, Fire, Death & 1988 & Kraze \\
\hline Burzum & Hvis Lyset Tar Oss & 1994 & Misanthropy \\
\hline Celtic Frost & Into the Pandemonium & 1987 & Noise \\
\hline Darkthrone & Under a Funeral Moon & 1993 & Peaceville \\
\hline Dimmu Borgir & $\begin{array}{l}\text { Enthrone Darkness } \\
\text { Triumphant }\end{array}$ & 1997 & Nuclear Blast \\
\hline Emperor & $\begin{array}{l}\text { Anthems to the Welkin at } \\
\text { Dusk }\end{array}$ & 1997 & Century Media \\
\hline Hellhammer & $\begin{array}{l}\text { Apocalyptic Raids 1990 } \\
\text { A.D. }\end{array}$ & 1984 & Noise \\
\hline Immortal & Pure Holocaust & 1993 & Osmose \\
\hline Mayhem & De Mysteriis Dom Sathanas & 1994 & Century Media \\
\hline Mercyful Fate & Don't Break the Oath & 1984 & Roadrunner \\
\hline Ved Buens Ende & Written in Waters & 1995 & Misanthropy \\
\hline Venom & Black Metal & 1982 & Combat \\
\hline Ulver & Nattens Madrigal & 1996 & Century Media \\
\hline $\begin{array}{l}\text { Wolves in the } \\
\text { Throne Room }\end{array}$ & Two Hunters & 2007 & Southern Lord \\
\hline
\end{tabular}




\section{BIBLIOGRAPHY}

Baddeley, Gavin. Lucifer Rising: A Book of Sin, Devil Worship and Rock 'n' Roll. London: Plexus, 1999.

Bayer, Gerd. Heavy Metal Music in Britain. Farnham, England: Ashgate, 2009.

Beste, Peter, and Johan Kugelberg. True Norwegian Black Metal: We Turn in the Night Consumed by Fire. Brooklyn, New York: Vice Books, 2008.

Blush, Steven. American Hair Metal. Los Angeles, CA: Feral House, 2006.

Ekeroth, Daniel. Swedish Death Metal. Brooklyn, NY: Bazillion Points Books, 2008.

Ernst, Rick. Get Thrashed: The Story of Thrash Metal. [New York]: Lightyear Entertainment, 2008.

Kahn-Harris, Keith. Extreme Metal: Music and Culture on the Edge. Oxford: Berg, 2007.

Kitts, Jeff, and Brad Tolinski. Guitar World Presents Nu-Metal. Milwaukee, WI: Hal Leonard, 2002.

Moynihan, Michael, and Didrik Søderlind. Lords of Chaos: The Bloody Rise of the Satanic Metal Underground. Venice, CA: Feral House, 1998.

Mudrian, Albert. Choosing Death: The Improbable History of Death Metal and Grindcore. Los Angeles, Calif.: Feral House, 2004.

Purcell, Natalie J. Death Metal Music: The Passion and Politics of a Subculture. Jefferson, N.C.: McFarland, 2003.

Sharpe-Young, Garry. A-Z of Black Metal. London: Cherry Red Books, 2001.

A-Z of Doom \& Gothic Metal. London: Cherry Red, 2003.

A-Z of Power Metal. London: Cherry Red, 2003.

—. Death Metal. New Plymouth, N.Z.: Zonda Books, 2008.

—. Thrash Metal. New Plymouth, N.Z.: Zonda Books, 2007.

Walser, Robert. Running With the Devil: Power, Gender and Madness in Heavy Metal Music. Middletown, Conn.: Wesleyan University Press, 1993.

Weinstein, Deena. Heavy Metal: The Music and Its Culture. [New York]: Da Capo Press, 2000.

Zebub, Bill. Black Metal: A Documentary. DVD. Directed by Bill Zebub. [USA]: Bill Zebub Productions, 2007. 